\title{
David Efird Postgraduate Essay Prize
}

Submissions are invited for the David Efird Postgraduate Essay Prize, which is sponsored jointly by Cambridge University Press and the British Society for the Philosophy of Religion. The winning entry will be published in Religious Studies and the winner awarded $£ 300$. The Prize was formerly referred to as the Religious Studies Postgraduate Essay Prize but was recently renamed in honour of David Efird, our former Co-Editor, who passed away in 2020.

The Prize caps an international competition that is open to all those who are registered for a postgraduate degree at the time of submission. The essay should treat a topic in the philosophy of religion and must not exceed 8,000 words in length. The judges reserve the right not to award the Prize if no submission of sufficient merit is received. All entries will be considered for publication in Religious Studies.

Essays should be submitted via the journal's electronic system. A special submission area has been established for entries in the Essay Prize competition. The author's name and contact details should not be included on the paper but must be submitted separately.

The closing date for entries is 31 December 2021. 